\title{
Dorsal Hippocampus Drives Context-Induced Cocaine Seeking via Inputs to Lateral Septum
}

\author{
Ellen M McGlinchey ${ }^{1,2}$ and Gary Aston-Jones*,2 \\ 'Department of Neurosciences, Medical University of South Carolina, Charleston, SC, USA; ${ }^{2}$ Brain Health Institute, Rutgers University and Rutgers \\ Biomedical and Health Sciences, Piscataway, NJ, USA
}

\begin{abstract}
Lateral septum (LS) has re-emerged as an important structure in reward and addiction; however, LS afferents that drive addiction behaviors are unknown. Here, we used a modified self-administration/reinstatement procedure combined with anatomical, pharmacological, and chemogenetic techniques to characterize LS, and hippocampal inputs to LS, in two established triggers of drug relapse - context- and cue-induced reinstatement of cocaine seeking. We found that inactivation of LS neurons attenuated both context- and cue-induced reinstatement of cocaine seeking. However, dorsal hippocampus inputs to LS showed enhanced neuronal activation (as measured by Fos expression) during context-induced, but not cue-induced reinstatement. Additionally, chemogenetic inhibition of dorsal, but not ventral, hippocampal inputs to LS specifically attenuated context-induced reinstatement. Together these findings elucidate the importance of LS in reinstatement of cocaine seeking, and indicate that dorsal hippocampal inputs to LS mediate context-, but not cue-induced, reinstatement of cocaine seeking.

Neuropsychopharmacology (2018) 43, 987-1000; doi:10.1038/npp.2017.144; published online 23 August 2017
\end{abstract}

\section{INTRODUCTION}

Lateral septum (LS), a brain structure within the limbic system, has re-emerged in the literature as a critical node in reward-related behaviors. Intracranial self-stimulation studies in both humans and rodents established LS as a rewardrelated structure (Heath, 1963; Olds and Milner, 1954). More recent studies implicated LS in addiction and relapse to several drugs of abuse (Cornish et al, 2012; Le Merrer et al, 2007; Luo et al, 2011; Sartor and Aston-Jones, 2012). Rats self-administer morphine into LS (Le Merrer et al, 2007), methamphetamine-seeking upregulates Fos expression in LS (Cornish et al, 2012), and pharmacological inhibition of LS blocks cocaine-conditioned place preference (Sartor and Aston-Jones, 2012).

LS is highly connected to brain regions associated with drug addiction, including ventral tegmental area (VTA), nucleus accumbens, lateral hypothalamus, and hippocampus (Risold and Swanson, 1997; Sheehan et al, 2004). Hippocampus provides the densest input to LS (Risold and Swanson, 1997), and is a critical structure involved in encoding, interpreting, and recalling contextual representations (Jarrard, 1993). Our laboratory revealed a circuit from dorsal hippocampal CA3 neurons to VTA via a relay in LS (Luo et al, 2011), indicating that LS may be an important

\footnotetext{
*Correspondence: Dr G Aston-Jones, Brain Health Institute, Rutgers University and Rutgers Behavioral and Health Sciences, 683 Hoes Lane West, SPH Suite 259, Piscataway, NJ 08854, USA, Tel: +I 732235 6077, Fax: + 732235 58|4, E-mail: aston.jones@rutgers.edu

Received 18 October 20 16; revised 3 June 20 17; accepted 3 July 20 I7; accepted article preview online II July 2017
}

region linking memories of salient contextual stimuli with associated rewards.

Different triggers of relapse (reinstatement of extinguished lever pressing in a rodent model) recruit distinct brain circuits. Inhibition of dorsal hippocampal neurons attenuates only context-, but not cue-induced reinstatement of cocaine seeking (Fuchs et al, 2005), ventral pallidum inhibition attenuates cue-induced, but not cocaine-primed reinstatement (Mahler et al, 2014), and pharmacological blockade of dopamine receptors in nucleus accumbens shell and core show dissociable roles in context- $v s$ cue-induced reinstatement of heroin seeking (Bossert et al, 2007). These results signify that specific brain regions drive particular reinstatement modalities. It is important to elucidate the neural circuitry involved in specific relapse triggers to identify potential targets for future therapeutics. LS could be a promising target to treat addiction given its involvement in multiple drugs of abuse and connections with reward-related regions. However, no studies to date have directly investigated inhibition of projections to LS during drug-seeking behaviors.

Here, we adapted a self-administration procedure to dissociate context- (Crombag and Shaham, 2002) vs discrete cue-induced (Meil and See, 1997) reinstatement within the same subjects, and used anatomical, pharmacological, and chemogenetic techniques to investigate inputs to LS that drive reinstatement behavior. We predicted that dorsal hippocampus drives specifically context-, but not cue-induced, reinstatement via its inputs to LS. 


\section{MATERIALS AND METHODS}

\section{Subjects}

Male Sprague Dawley rats ( $n=112$; arrival weight $275-325$ g; Charles River, Raleigh, NC, USA) were single or double housed under a reverse $12: 12 \mathrm{~h}$ light cycle with ad libitum food and water. The Institutional Animal Care and Use Committees at the Medical University of South Carolina and Rutgers University approved of all laboratory procedures. Procedures were conducted according to the Guide for the Care and Use of Laboratory Animals. Rats were handled daily after a 3-day acclimation period at the facility; all experiments were performed in the rats' active (dark) phase.

\section{Intravenous Catheter Surgery for Self-Administration}

All rats were anesthetized with a mixture of ketamine/ xylazine ( 56.5 and $8.7 \mathrm{mg} / \mathrm{kg}$, i.p., respectively) followed by an injection of an analgesic (meloxicam, $1 \mathrm{mg} / \mathrm{kg}$ or rimadyl, $5 \mathrm{mg} / \mathrm{kg}$; s.c.). Rats were then implanted with an indwelling catheter (modified 22ga cannula, Plastics One) into the jugular vein that exited the body via a biopsy hole on the back. Catheters were flushed with cefazolin $(0.1 \mathrm{ml} ; 100 \mathrm{mg} /$ $\mathrm{ml})$ and heparin $(0.1 \mathrm{ml} ; 100 \mathrm{U} / \mathrm{ml})$ immediately following surgery, daily beginning 3 days after surgery, and continuing throughout self-administration. Rats were monitored daily for post-operative care and allowed to recover for a minimum of 1 week after surgery before beginning behavioral training.

\section{Self-Administration and Extinction Training}

A modified self-administration procedure was adapted to dissociate reinstatement to contexts $v s$ discrete cues using a within-subjects approach (Figure $1 \mathrm{a}$ and b). All selfadministration chambers were within a sound-attenuating box, controlled by Med-PC IV software (Med Associates, St Albans, VT, USA) and equipped with two retractable levers with cue lights above each lever and a house light on the opposite wall. Two contextually different chambers were used during self-administration training. One context was in a smaller self-administration chamber with black circled wallpaper, grid flooring, lemon odor, and a red house light. The alternative context was a larger self-administration chamber with black striped wallpaper, mesh flooring, vanilla odor, and a white house light (Figure 1b). Rats learned selfadministration in one of the contexts. No food training was performed. Responses on the active lever (fixed ratio-1 schedule) resulted in cocaine infusions $(0.2 \mathrm{mg} / 50 \mu \mathrm{linfu}-$ sion; cocaine $\mathrm{HCl}$ dissolved in $0.9 \%$ sterile saline, NIDA) paired with discrete light and tone cues (white cue light above the active lever and a $78 \mathrm{~dB}, 2.9 \mathrm{kHz}$ tone) during training. After each reward a $20 \mathrm{~s}$ timeout occurred (signaled by turning off the house light) when additional presses did not yield rewards or cues. Presses on the inactive lever were recorded, but had no programmed consequences. After 10+ $\mathrm{d}$ of criterion self-administration performance (at least 10 infusions per $2 \mathrm{~h}$ session), rats were placed into the alternative context for extinction training. Some rats received 1-4 additional days of criterion self-administration training beyond the standard 10 days. Rats that received additional self-administration days showed consistent lever pressing behavior similarly to the rats that received 10 days of selfadministration training. During extinction training, responding on either lever did not result in discrete cue presentations or cocaine infusions. Rats received extinction training for a minimum of 7 days and until they met the criteria of $<25$ active lever presses for 2 or more consecutive days. Rats in the extinction group underwent self-administration and extinction training, but were given a final extinction session upon reaching extinction criteria performance before being killed for Fos.

\section{Reinstatement Testing}

Upon meeting criteria performance for extinction, rats were counterbalanced to receive a context- or a cue-induced reinstatement test (Figure 1a). For context-induced reinstatement, rats returned to their original training context, but did not get the contingent discrete light and tone cues or cocaine they received during self-administration (ABA design; Crombag and Shaham, 2002). For cue-induced reinstatement, rats stayed in their extinction context, but responding on the active lever resulted in the presentation of the discrete light and tone cues (but no cocaine) given during training (ABB design; Bossert et al, 2007; Adhikary et al, 2016). Between reinstatement tests, rats were placed back into their extinction environment until they re-extinguished their lever pressing behavior before initiating the alternative reinstatement test. Figure $1 \mathrm{c}$ and $\mathrm{d}$ include all rats in Experiments 1 and 2 and all control rats in Experiments 3 and 4.

\section{Experiment 1: Fos Expression in LS and HPC}

Reinstatement testing for Fos measurements. Following intravenous catheter surgery and self-administration and extinction training, rats were perfused immediately following $2 \mathrm{~h}$ sessions of context reinstatement $(n=8)$, cued reinstatement $(n=6)$, extinction $(n=5)$, or yoked saline context $(n=5)$. For the yoked saline group (Neisewander et al, 2000), rats were placed in the same operant environment as cocaine self-administering rats, but their lever presses had no programmed outcomes. Instead, rats were paired to cocaine self-administering rats and received yoked passive infusions of saline and light/tone pairings to the same degree as their self-administering counterparts. They then were placed in the alternative environment for a minimum of 7 days, and then re-exposed to their original context. This examined whether activation of brain regions occurred upon returning to a familiar, but neutral (non-drug) context. For all groups, Fos labeling should reflect neural activity at $\sim 0-30 \mathrm{~min}$ in the test session (the period of peak lever responding; Smith et al, 2009; Mahler and Aston-Jones, 2012) as maximal Fos induction occurs $\sim 90-120 \mathrm{~min}$ following neuronal activation (Müller et al, 1984; Young et al, 1991).

Tissue preparation for immunohistochemistry. Rats were deeply anesthetized with ketamine/xylazine and perfused with $0.9 \%$ saline followed by $4 \%$ paraformaldehyde immediately following their reinstatement test for Fos analysis. Brains were removed and postfixed for $24 \mathrm{~h}$, then transferred to $20 \%$ sucrose-azide solution and stored at $4{ }^{\circ} \mathrm{C}$.

Brains were frozen on dry ice, and sliced into $40 \mu \mathrm{m}$ coronal sections on a cryostat (Leica). Brain slices were 
a

\begin{tabular}{|c|c|c|c|}
$\begin{array}{c}\text { Self-administration } \\
\text { (Context A or B) }\end{array}$ & $\begin{array}{c}\text { Extinction } \\
\text { (Opposite context) }\end{array}$ & Cue-induced & Reinstatement (counterbalanced) \\
\hline $\begin{array}{c}\text { Contingent } \\
\text { light/tone cues (CS+) }\end{array}$ & No light/tones cues & $\begin{array}{c}\text { Remain in extinction } \\
\text { context with CS+ cues }\end{array}$ & $\begin{array}{c}\text { Return to training } \\
\text { environment without } \\
\text { CS+ cues }\end{array}$
\end{tabular}

b

\begin{tabular}{|c|c|c|c|}
\cline { 2 - 4 } \multicolumn{1}{c|}{} & Visual stimuli & Tactile stimuli & Olfactory stimuli \\
\hline Context A & $\begin{array}{c}\text { Shorter SA box, circles on walls, } \\
\text { red house light }\end{array}$ & Grid floor & Lemon odor \\
\hline Context B & $\begin{array}{c}\text { Taller SA box, stripes on walls, } \\
\text { white house light }\end{array}$ & Mesh floor & Vanilla odor \\
\hline
\end{tabular}

C

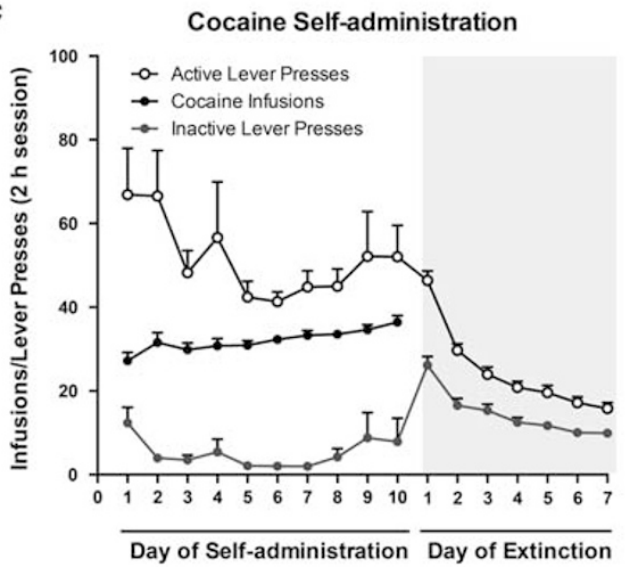

d

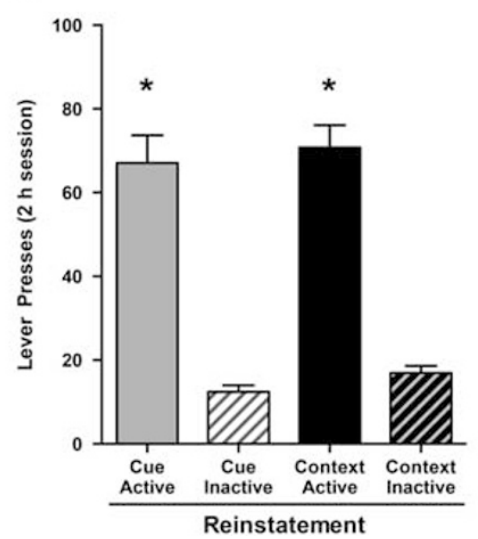

Figure I Experimental design, behavioral training, and testing. (a) Experimental design of the self-administration procedure that provides within-subjects testing of context- and cue-induced reinstatement of drug seeking. (b) Stimulus components of each training environment. (c) Mean behavioral performance of all rats during cocaine self-administration and extinction training $(n=91)$. Data reflect the minimum 10 days of total self-administration training that every rat received and Day I of self-administration indicates the first day of criteria performance. (d) Mean active and inactive lever presses during $2 \mathrm{~h}$ cue- $(n=66$; gray bar) or context-induced reinstatement tests $(n=68$; black bar). Bar graphs represent mean \pm standard error of mean (SEM). Note that context and cues produce similar amounts of reinstatement responding.

sequentially placed in six wells $(240 \mu \mathrm{m}$ apart per well) and collected in $0.1 \mathrm{M}$ phosphate buffered saline with $1 \%$ sodium azide (PBS-Az).

Immunohistochemistry staining procedures. Immunohistochemistry procedures for Fos labeling were similar to our previously published methods (McGlinchey et al, 2016). In brief: tissue was quenched with hydrogen peroxide, washed with PBS, and blocked in a $2 \%$ normal donkey serum in PBS with Triton for $2 \mathrm{~h}$. Tissue was incubated in a rabbit anti-Fos primary antibody (1:10 000; CalBioChem; PC38) overnight, and then incubated in a biotinylated donkey anti-rabbit secondary antibody (1:500; Jackson ImmunoResearch Laboratories) for $2 \mathrm{~h}$ followed by incubation in an avidinbiotin complex solution $(1: 500)$ for $1.5 \mathrm{~h}$. The tissue was then reacted with 3,3'-diaminobenzidine (DAB; Sigma) to visualize antibody location. The DAB solution was mixed with Tris-buffer, hydrogen peroxide, and nickel ammonium sulfate to produce a black Fos nuclear stain.

Fos quantification. Brain tissue with Fos labeling was photographed at $\times 10$ magnification using a Leica DMRXA research microscope with OpenLab software (Improvision). Regions photographed included the dorsal hippocampus (2.52-3.48 $\mathrm{mm}$ posterior to bregma), rostral LS (2.16$1.20 \mathrm{~mm}$ anterior to bregma), caudal LS (1.08-0.12 mm anterior to bregma) and ventral hippocampus (5.04-6.12 mm posterior to bregma). Three brain sections within each structure for each group (extinction, cue- and, contextinduced reinstatement, and yoked saline) were photographed for cell quantification. An individual blinded to groups quantified the number of Fos cells using standardized thresholds for size and intensity in Image J (NIH).

\section{Experiment 2: Pharmacological Inhibition of LS}

Intravenous catheter surgery and implantation of bilateral cannulae in LS. Rats were implanted with an iv catheter (described above) and an intracerebral guide composed of bilateral cannulae that were $1.2 \mathrm{~mm}$ apart from center-tocenter (26 ga; $0.19 \mathrm{~mm}$ anterior to bregma, $3.9 \mathrm{~mm}$ ventral to skull; $n=12$ ). These guide cannulae terminated $2 \mathrm{~mm}$ above LS, and were attached to the skull using dental cement supported by four jeweler screws. Guide cannulae were occluded by insertion of sterilized stylets (Plastics One) the same length as the guide cannulae. Guide cannulae and stylets were topped with an aluminum dust cap for additional protection (Plastics One).

Behavioral training and reinstatement testing. Behavioral training was initiated as described above. Following the last extinction session, rats were acclimated to the microinjection 
procedure by gently restraining the rat and lowering the injectors into LS (33ga, protruding $2 \mathrm{~mm}$ below the cannula, Plastics One); no infusions were made. Rats received a total of four reinstatements (two context, two cue; alternating, randomized, and counterbalanced). Rats received a minimum of two consecutive, criterion extinction sessions $(<25$ active lever presses) in their original extinction context between reinstatement tests.

On each reinstatement test day, rats received microjections of either artificial cerebral spinal fluid (aCSF, $0.5 \mu \mathrm{l} / \mathrm{side}$ ) or a cocktail of the $\mathrm{GABA}_{\mathrm{A}}$ and $\mathrm{GABA}_{\mathrm{B}}$ agonists, baclofen and muscimol (B-M; $1 \mathrm{mM}$ and $0.1 \mathrm{mM}$, respectively; $0.5 \mu \mathrm{l} /$ side, Luo et al, 2011) into LS immediately prior to each reinstatement test. The order of the microinjections was the first two microinjections were aCSF, followed by two $\mathrm{B}-\mathrm{M}$ microinjections, or vice versa. The injectors remained in place for one minute after microinjection to reduce diffusion up the cannula track. Then rats were immediately placed in their reinstatement chamber for testing.

Locomotor testing. Rats were assessed for general locomotor activity to ensure that any pharmacological results were not due to nonspecific motor effects. Open field locomotor chambers (Omnitech Electronics, Inc.) consisted of three sensor pairs each configured with 16 infrared light photobeams to record horizontal $X$ - and $Y$-axes, and a $Z$-axis for rearing/vertical activity. Each locomotor chamber was either contained within an environmental isolation chamber or surrounded by a black curtain. The locomotor boxes were equipped with either Fusion or VersaMax software (Omnitech Electronics, Inc.) to record horizontal and vertical beam breaks and total distance traveled. Rats received locomotor testing upon completion of all reinstatement testing. Rats acclimated to the locomotor boxes for 2 days ( $2 \mathrm{~h}$ sessions) to reduce novelty-induced locomotion. The following day, rats were microinjected with either B-M or vehicle (aCSF) immediately before placement into the locomotor chamber. Rats then received a no-injection day in the locomotor chamber, followed by the opposite microinjection of either B-M or aCSF prior to the 5th locomotor day. The order of $\mathrm{B}-\mathrm{M}$ vs aCSF microinjections was randomized and counterbalanced.

Staining procedures and localization of injection sites. Rats that received cannulae for B-M microinjections into LS were killed after behavioral testing was complete. To localize microinjection sites, rats were deeply anesthetized with ketamine/xylazine, rapidly decapitated, and the brain flash frozen with 2-methylbutane (Fischer Scientific) that was chilled in a $-80^{\circ} \mathrm{C}$ freezer for at least 30 min prior. The brain was then placed in $\mathrm{a}-20^{\circ} \mathrm{C}$ freezer until sectioning.

LS brain slices were collected sequentially across 3 wells, and slices were mounted, stained with neutral red or crystal violet, and coverslipped. Injection sites were verified using a Leica DMRXA research microscope.

\section{Experiment 3: Retrograde Tracer and Fos Labeling in HPC-LS Circuit}

Intravenous catheter surgery and injection of retrograde tracer in LS. Following intravenous catheter surgery, rats in Experiment 3 received a unilateral microinjection of cholera toxin $\beta$ subunit (CTb, 40-60 nl; $1 \%$ dissolved in $0.1 \mathrm{M}$ phosphate buffer, Sigma) into LS $(n=30)$. Injections were made at $0.25 \mathrm{~mm}$ rostral to bregma, $0.6 \mathrm{~mm}$ from midline, and $5.0 \mathrm{~mm}$ ventral to skull surface using a glass micropipette (15-20 $\mu \mathrm{m}$ diameter tip) and a pneumatic pressure source (Picospritzer; General Value, Inc.) Pressure injections were made over a 2 min period, and pipettes remained in place for $10-15 \mathrm{~min}$ to minimize diffusion along the pipette track.

Reinstatement testing, tissue preparation, and staining procedures for Fos/CTb labeling. Rats were trained to selfadminister cocaine, subjected to extinction, and then tested for reinstatement of cocaine seeking as described above. Similar to Experiment 1, rats were perfused immediately following $2 \mathrm{~h}$ sessions of context reinstatement, cued reinstatement, or extinction to capture Fos activity within the first $30 \mathrm{~min}$ of the test.

Brain tissue was first stained for Fos using the same methods as described in Experiment 1. For CTb staining, the same tissue stained for Fos for this experiment was incubated with goat anti-CTb primary antibody (1:20000; List Biological Laboratories; \#703), and then transferred to a biotinylated donkey anti-goat secondary antibody (1:500; Jackson ImmunoResearch Laboratories). The DAB reaction produced a brown cytoplasmic stain for CTb. Brain slices were mounted on glass slides, dehydrated with alcohols and xylenes, and coverslipped with DPX (Sigma). One rat with a retrograde tracer injection that was mostly in medial septum (rather than the target LS) was excluded from analyses.

Fos and CTb quantification. LS sections were photographed using a $\times 5$ objective with Openlab software, and compared to rat atlas sections of LS (Paxinos and Watson, 2007) to localize CTb injection sites. Three tissue sections per rat representing rostral, intermediate, and caudal levels were quantified for each LS afferent (dorsal hippocampus; ventral hippocampus; and basolateral amygdala, BLA) for each of the extinction, context-, and cue-induced reinstatement groups. These afferent structures were photographed with a $\times 10$ objective on a Leica microscope and stitched together automatically using the Stereoinvestigator Virtual Slice module (MBF Biosciences). Tissue sections from each rat were taken at similar rostrocaudal levels for each structure to ensure that quantified areas were similar across animals. Structure borders were defined based on the rat atlas (Paxinos and Watson, 2007). The total numbers of CTblabeled neurons (with or without Fos) within each LS afferent structure were manually counted for each of the three tissue sections per rat (sections were at least $240 \mu \mathrm{m}$ apart to prevent double counting). Dorsal hippocampal neurons ipsilateral and contralateral to the $\mathrm{CTb}$ injections were quantified, as both projections densely innervate LS (Risold and Swanson, 1997). Ventral hippocampal and BLA neurons only ipsilateral to the $\mathrm{CTb}$ injections were quantified, as their contralateral projections are not dense. The percentage of $\mathrm{CTb}+$ cells that expressed Fos was determined for each tissue section. Percentages of retrogradely labeled neurons that expressed Fos were analyzed to normalize for relative strength of projections and 
effectiveness of tracer injections. Means of these percentages were computed for each rat, and these means were averaged across behavioral groups for each brain region.

\section{Experiment 4: DREADD-Mediated Inhibition of HPC-LS Circuit}

Injection of DREADDs in hippocampus and CNO in LS. Rats assigned to DREADD (Designer Receptors Exclusively Activated by Designer Drugs, Armbruster et al, 2007) experiments received surgery to implant an intravenous catheter followed by bilateral microinjections of a lentivirus or adeno-associated virus (AAV) vector with the DREADD or GFP gene driven under a synapsin promoter. Vector injections were aimed at the dorsal CA3 or ventral CA1 regions of the hippocampus. The lentivirus DREADD construct contained the hM4Di gene fused to a hemoagglutanin (HA) tag and a GFP reporter tag (lentihsyn-hM4Di-HA-EGFP; custom packaged by University of Pennsylvania vector core). The AAV DREADD construct contained the hM4Di gene fused to an mCherry tag (AAV8hsyn-hM4Di-mcherry; University of North Carolina (UNC) a

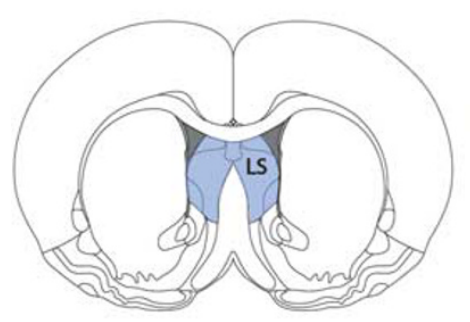

b

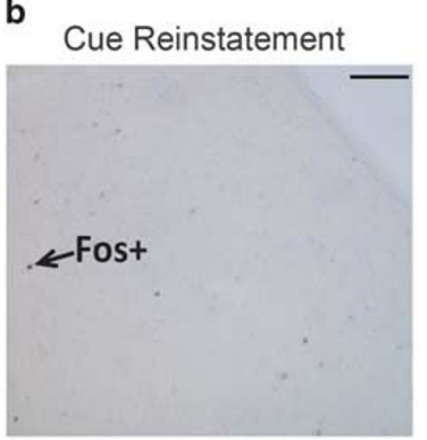

d

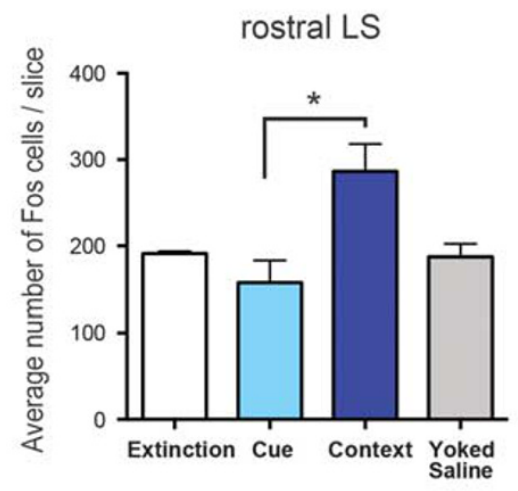

e

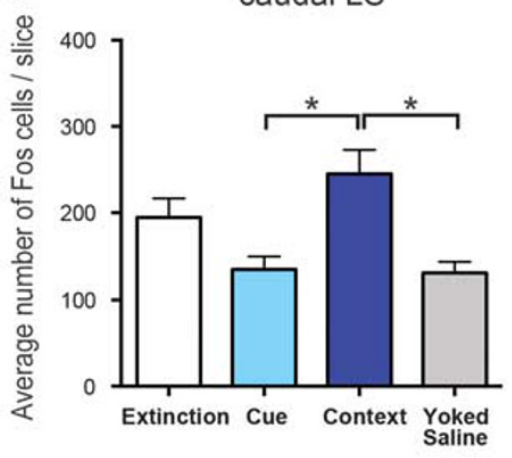

c

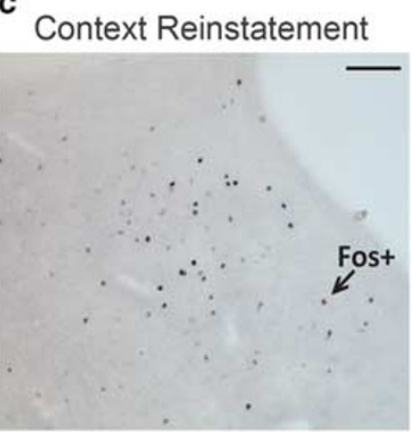

caudal LS

g
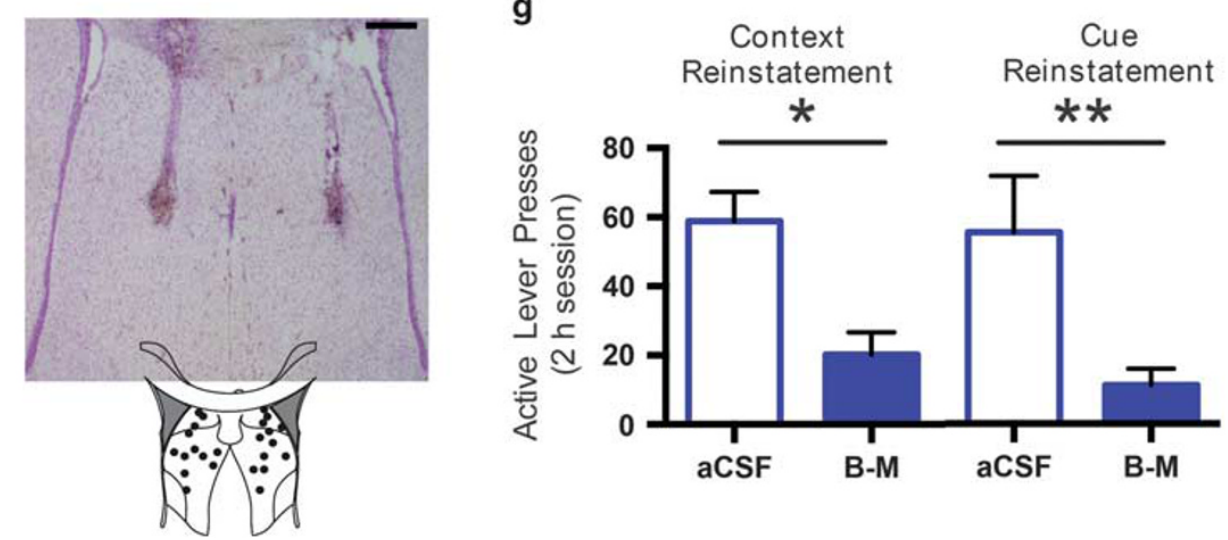

Figure 2 Fos expression and functional inhibition of lateral septum (LS) neurons during context- and cue-induced reinstatement of cocaine seeking. (a) Location of LS in a rat atlas coronal section $(0.72 \mathrm{~mm}$ anterior to bregma; Paxinos and Watson, 2007) and (b) representative photomicrographs of Fos expression in LS during a cue- or (c) context-induced reinstatement test. Scale bars, $100 \mu \mathrm{m}$. Whole images adjusted for contrast and brightness in representative tissue for cue-induced reinstatement. (d) Context reinstatement (dark blue bars, $n=8$ ) induced a greater number of Fos + cells compared to cue-induced reinstatement (light blue bars, $n=6$ ) in rostral LS $(* P<0.05)$ or $(e)$ compared to cue-induced reinstatement or yoked saline rats (gray bars, $n=5$ ) in caudal LS (*P $<0.05)$. White bars represent extinction group, $n=5$. SEM indicated by error bars. (f) Representative photomicrograph of cannula injection sites in LS (Nissl stain, frontal section, dorsal up, midline at center). Brain atlas inset shows bilateral injection sites across all rats (black circles; $n=12$ ). Scale bar, $200 \mu \mathrm{m}$. (g) Microinjections of the inhibitory cocktail baclofen plus muscimol (B-M, solid blue bar) into LS attenuated context-induced reinstatement $(* P<0.05)$ and cue-induced reinstatement relative to vehicle/aCSF (open blue bar) microinjections $(* * P<0.0 \mathrm{I})$. n.S. $=$ not significant. 
vector core). The GFP control virus was driven by the same neuronal promoter, but lacked the hM4Di gene and used to assess nonspecific effects produced by the vector infection and gene expression or CNO microinjections (AAV8-hsynEGFP; UNC vector core). Dorsal hippocampal (3.2 mm posterior to bregma, $3.2 \mathrm{~mm}$ from midline, $3.9 \mathrm{~mm}$ ventral to a
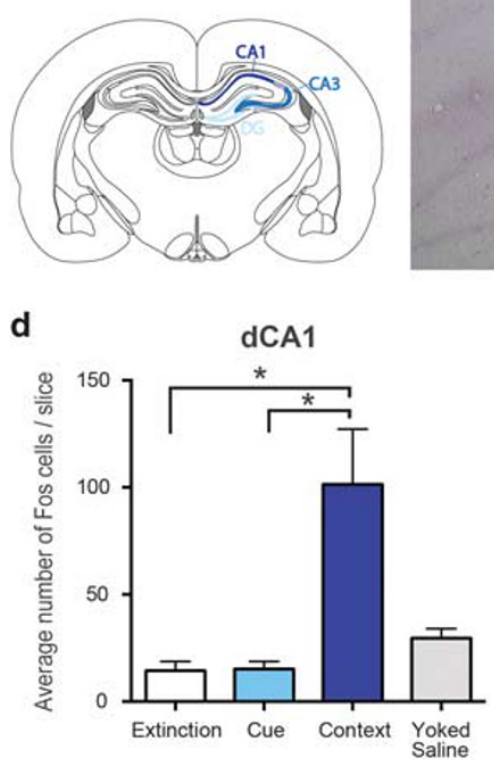

g

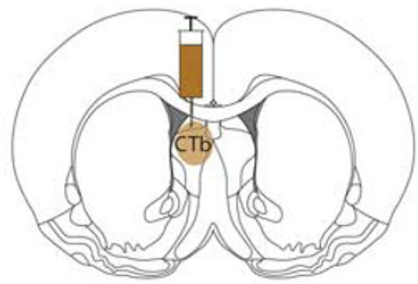

b
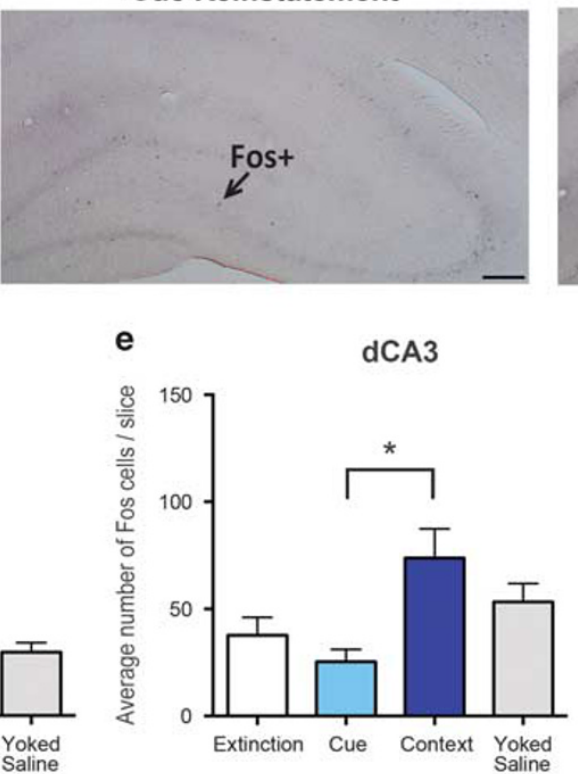

h

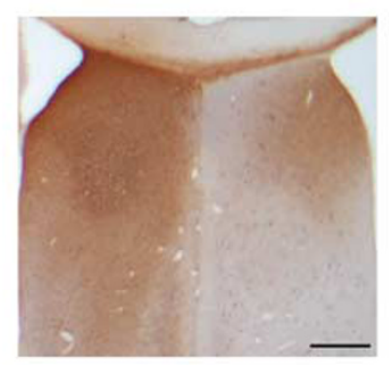

C Context Reinstatement
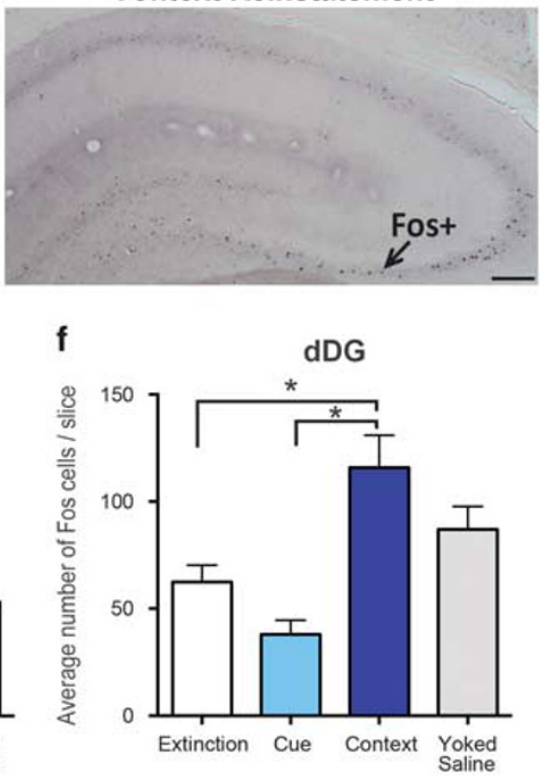

i

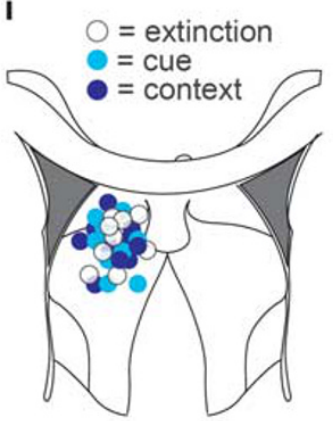

j

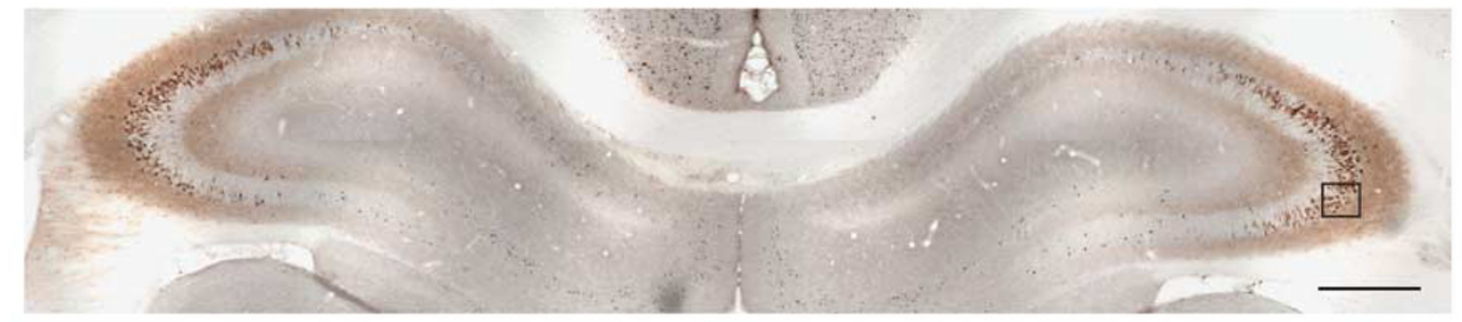

k

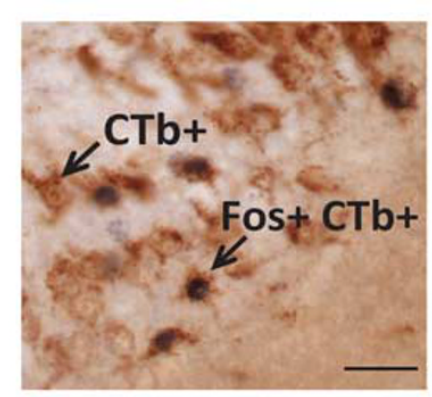

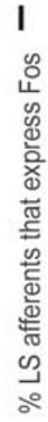

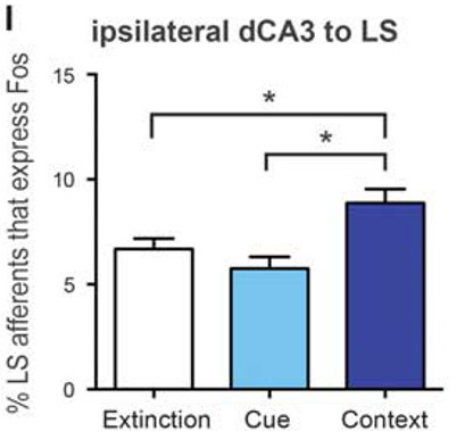

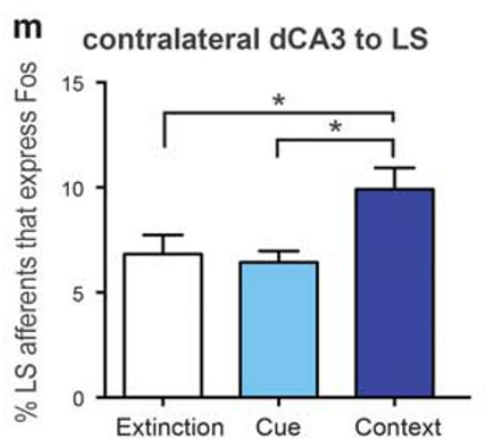


skull), and ventral hippocampal $(5.7 \mathrm{~mm}$ posterior to bregma, $5.3 \mathrm{~mm}$ from midline, $7.8 \mathrm{~mm}$ ventral to skull) injections were made using a glass micropipette $(30-40 \mu \mathrm{m}$ diameter tip) and a pneumatic pressure source (Picospritzer). Injection volumes ranged between 1.0 and $1.5 \mu \mathrm{l}$ per hemisphere. Pressure injections targeting dorsal hippocampus ( $n=23$; 14 hM4Di, nine GFP controls) were made over a $10 \mathrm{~min}$ period and pipettes remained in place for 10-20 min to minimize diffusion along the pipette track. Pipettes for ventral hippocampus injections $(n=19 ; 11 \mathrm{hM} 4 \mathrm{Di}, 8 \mathrm{GFP}$ controls) remained in place only for a few minutes to increase diffusion up the pipette track to infect a greater number of ventral CA1 cells. Subsequently, rats were surgically implanted with cannula aimed above LS for later CNO administration into LS. The methods for this procedure are described above.

Reinstatement testing. Rats with hM4Di DREADD or GFP (control) expression in hippocampus were microinjected with CNO $(1 \mathrm{mM})$ or aCSF $(0.3 \mu \mathrm{l} /$ side $)$ onto hM4Di- or GFP-expressing terminals in LS to determine if specific neural circuits are necessary for reinstatement behavior. Reinstatement testing and CNO microinjections in the DREADD experiments did not begin until 5 weeks after the initial virus injections to provide sufficient time to express the hM4Di receptors in hippocampal terminals in LS.

The injectors remained in place for one minute after microinjection and then the rats were immediately placed in their reinstatement chamber for testing. One rat died and another lost his cranial implant before completing reinstatement testing; these rats were excluded from analyses.

Locomotor testing. After all reinstatement testing was complete, rats were assessed for general locomotor activity. As similarly described above, the rats acclimated to the locomotor chamber for $2 \mathrm{~d}$, were microinjected with either $\mathrm{CNO}$ or aCSF immediately before locomotor testing, received a no-injection day in the locomotor chamber on the 4 th day, and then given the opposite microinjection of either $\mathrm{CNO}$ or aCSF prior to the 5 th day. The order in which rats received CNO vs aCSF microinjections was randomized and counterbalanced.
Immunohistochemistry staining procedures \& localization and injections sites. Brain tissue with $\mathrm{hM} 4 \mathrm{Di}$ viral injections was incubated in mouse anti-HA (1:1000; Covance; MMS-101P) or rabbit anti-DsRed (1:500; Clontech; 632496) primary antibodies, followed by biotinylated donkey anti-mouse ( $1: 500$; Jackson ImmunoResearch Laboratories) or donkey anti-rabbit (1:500; Jackson ImmunoResearch Laboratories) secondary antibodies, respectively. Control virus brain tissue (synapsin promoter-driven GFP virus without the DREADD gene) was incubated with chicken anti-GFP primary antibody (1:2000; Abcam; ab13970) and donkey anti-chicken secondary antibody (1:500; Jackson ImmunoResearch Laboratories). DAB staining procedures were similar to those described above for Fos staining; nickel ammonium sulfate was used to intensify staining at DREADD injection sites and at hM4Di-expressing terminals. Sections were then mounted and counterstained with neutral red, dehydrated, and coverslipped. Hippocampal injection sites and terminals in LS were examined on a Leica DMRXA research microscope. Rats without expression in hippocampus $(n=2)$ or with CNO microinjection sites in the ventricle ( $n=11$; for all experiments) were excluded from analyses.

\section{Data Analysis}

Self-administration and reinstatement data were analyzed with repeated measures one-way or two-way analyses of variance (ANOVAs) with Bonferroni multiple comparison analyses as appropriate. One-way ANOVAs with Tukey post hoc analyses were used to analyze the average number of Fos cells or the percentages of Fos-positive LS afferents between groups. Two-way repeated measures ANOVAs (drug $\mathrm{x}$ reinstatement) were used to analyze active lever responding during reinstatement following vehicle (aCSF) or drug (B-M or $\mathrm{CNO}$ ) microinjections. Locomotor activity across the $2 \mathrm{~h}$ session was analyzed using a paired $t$-test. Non-parametric Kruskal-Wallis tests with Dunn's post hoc analyses or Wilcoxon matched-pairs signed rank tests were used when data were not normally distributed according to a D'Agostino-Pearson omnibus normality test. All statistics were twotailed. Data analyses were performed with Prism version 6 or SPSS 21 (IBM).

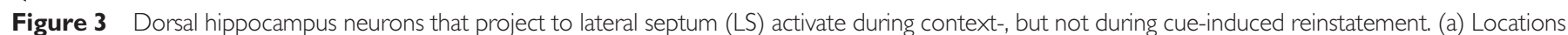

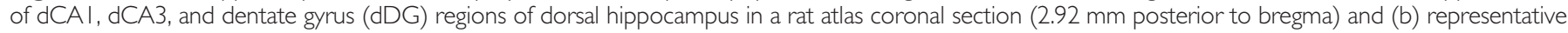

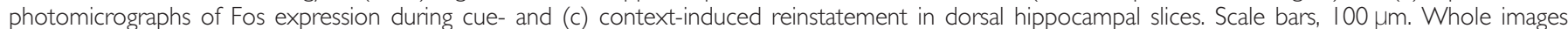

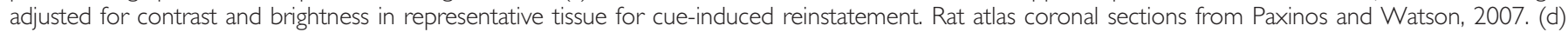
Context reinstatement (dark blue bar, $n=8$ ) induced more Fos + cells than cue-induced reinstatement (light blue bar, $n=6)$ or extinction ( white bar, $n=5$ ) in

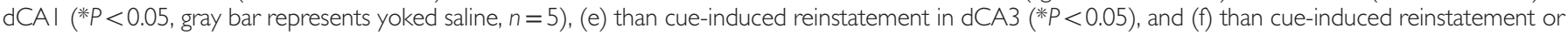
extinction in $\mathrm{dDG}(* \mathrm{P}<0.05)$. (g) Illustration of unilateral retrograde tracer $(\mathrm{CTb})$ injection into LS. (h) Representative photomicrograph of a unilateral CTb

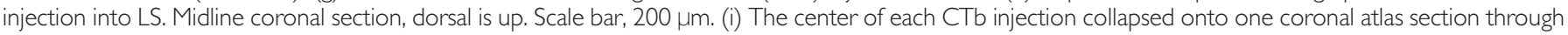
LS (0.72 mm anterior to bregma, Paxinos and Watson, 2007). White circles indicate rats assigned to the extinction group, light blue circles indicate rats

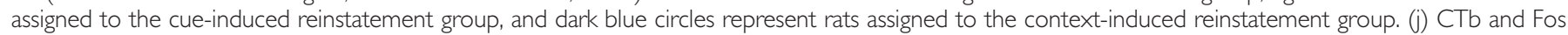

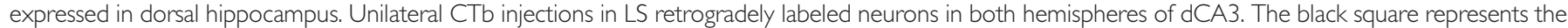

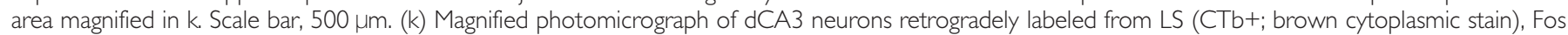

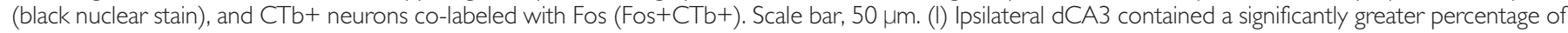

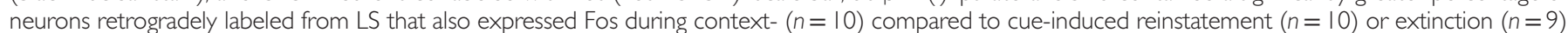

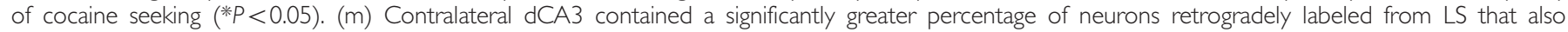
expressed Fos during context- compared to cue-induced reinstatement or extinction of cocaine seeking (*P<0.05). SEM indicated by error bars. 


\section{RESULTS}

\section{Similar Behavior During Context- and Cue-Induced Reinstatement of Cocaine Seeking}

Experiments used a modified self-administration/reinstatement procedure to dissociate context- and discrete cue-induced reinstatement within the same subjects (see Materials and Methods; Figure 1a-d). During self-administration, rats showed a preference for the active (drugassociated) lever compared to the inactive lever throughout training (two-way RM ANOVA; $\mathrm{F}_{1,180}=104.2, P<0.0001$ ), and extinguished this behavior over extinction days (two-way ANOVA, $\mathrm{F}_{6,546}=65.8, P<0.0001$ ). The number of active lever presses did not differ between days 1 and 10 of self-administration (one-way RM ANOVA, $\mathrm{F}_{9,90}=1.59$, $P=0.19$ ). We observed robust and similar lever pressing during context- and cue-induced reinstatement behaviors (Figure 1d; two-way RM ANOVA; no test-lever interaction: $\mathrm{F}_{1,132}=0.01, P=0.92$; no main effect of test: $\mathrm{F}_{1,132}=0.74$, $P=0.39$; main effect of lever: $\mathrm{F}_{1,132}=166, P<0.0001$ ). Selfadministration and extinction also were equivalent in the two training contexts (Supplementary Figure S1a-d).

\section{More Fos Activation in LS Neurons Following Context- vs Cue-Induced Reinstatement of Cocaine Seeking}

To determine if context- or cue-induced reinstatement differentially activated LS neurons, we assessed the amount of Fos-protein induction using immunohistochemistry. We analyzed rostral and caudal subregions of LS separately due to functional specificity in their circuitry (Luo et al, 2011; Risold and Swanson, 1997; Sartor and Aston-Jones, 2012). Results showed that LS neurons (both rostral and caudal subregions of LS) expressed more Fos during context- $v s$ cue-induced reinstatement (Figure 2a-e; one-way ANOVA; rostral LS: $\mathrm{F}_{3,20}=5.5, P=0.006$; caudal LS: $\left.\mathrm{F}_{3,20}=6.4, P=0.003\right)$. The amounts of Fos in LS did not differ significantly during context reinstatement $v s$ extinction responding, although there was a trend for higher Fos during context reinstatement especially in rostral LS $(P=0.07)$. There was also a significant increase in the number of Fos cells during context reinstatement $v s$ yoked saline rats in caudal LS and a strong trend in rostral LS (caudal LS: $P=0.009$; rostral LS: $P=0.058$ ).

\section{Inactivation of LS Attenuates Context- and Cue-Induced Reinstatement of Cocaine Seeking}

Next, we microinjected a cocktail of the $\mathrm{GABA}_{\mathrm{A}}$ and $\mathrm{GABA}_{\mathrm{B}}$ agonists, baclofen and muscimol (B-M), into LS to inhibit neural activity during context- or cue-induced reinstatement. $\mathrm{B}-\mathrm{M}$ in LS attenuated both context-induced $(P=0.02)$ and cue-induced $(P=0.009)$ reinstatement compared to microinjections of artificial cerebral spinal fluid (aCSF; Figure $2 \mathrm{f}$ and g; two-way RM ANOVA, main effect of drug: $\left.\mathrm{F}_{1,22}=17.71, P=0.0004\right)$. These results indicate that LS has a functional role for both reinstatement modalities, but is Fos-activated only during context-induced reinstatement.

General locomotion as measured by total horizontal and vertical activity, and total distance traveled, remained intact after B-M injections in LS, indicating no nonspecific motor effects (Supplementary Figure S2) of this treatment.

Dorsal Hippocampal Neurons that Project to LS Express Fos Preferentially During Context- $v s$ Cue-Induced Reinstatement of Cocaine Seeking

We next examined the possible roles of different hippocampal regions in reinstatement of cocaine seeking. Fos data revealed that all dorsal hippocampal regions (dorsal CA1, dorsal CA3, and dorsal dentate gyrus; dDG) expressed more Fos during context- $v s$ cue-induced reinstatement (Figure 3a-f; Kruskal-Wallis; dCA1: $\mathrm{H}_{3,20}=11.7, P=0.008$; one-way ANOVA; dCA3: $\mathrm{F}_{3,20}=4.2, \quad P=0.018 ; \quad \mathrm{dDG}$; $\left.\mathrm{F}_{3,20}=8.6, P=0.0007\right)$. All septal and hippocampal regions expressed more Fos+ cells when rats returned to drugassociated $v s$ yoked saline-associated contexts.

We also examined hippocampal inputs to LS using this behavioral procedure. We injected the retrograde tracer, cholera toxin subunit $\beta$ (CTb) unilaterally into LS, and examined the percentage of neurons retrogradely labeled in hippocampus that expressed Fos (Figure 3g-k). Both hemispheres of the dorsal CA3 region (dCA3) of the hippocampus projected nearly equally to one hemisphere of LS (Figure $3 j$ and Supplementary Table S1). We found that ipsilateral and contralateral inputs from dCA3 to LS expressed more Fos during context- than during cue-induced reinstatement or extinction (one-way ANOVA; $\mathrm{F}_{2,26}=7.7,5.2 ; P<0.02$; Figure $3 \mathrm{l}$ and $\mathrm{m}$ ), indicating that dCA3 inputs to LS activate preferentially to drug-associated contexts.

\section{Chemogenetic Inhibition of Dorsal Hippocampal Terminals in LS Attenuates Context-Induced but not Cue-Induced Reinstatement of Cocaine Seeking}

We next sought to determine if hippocampal inputs to LS have a causal role in context- or cue-induced reinstatement. We bilaterally expressed the inhibitory hM4Di DREADD (Armbruster et al, 2007) under a synapsin promoter (lenti-hsyn-hM4Di-HA-EGFP or AAV-hsyn-hM4Di-mcherry; Mahler et al, 2014) in dCA3 and microinjected the DREADD agonist clozapine- $\mathrm{N}$-oxide (CNO) bilaterally into LS (Figure $4 a-d)$. The hM4Di receptors were transported to dCA3 terminals in LS, as visualized by an antibody to the tag fused to the hM4Di receptor (Figure 4c). Microinjections of CNO vs aCSF among hM4Di-expressing dCA3 terminals in LS showed a nearly significant main effect of drug during context-induced $v s$ cue-induced reinstatement of cocaine seeking (Figure 4e; RM two-way ANOVA, $\mathrm{F}_{1,18}=3.89$, $P=0.06)$. Similar inhibition of this circuit did not alter total horizontal activity, vertical activity, or distance traveled during locomotor testing (Supplementary Figure S3). In addition, CNO microinjections in LS did not alter reinstatement behavior in rats with hippocampal injections of a control virus lacking the hM4Di gene (AAV-hsyn-EGFP; Figure 4f; effect of drug: $\mathrm{F}_{1,12}=0.25, P=0.62$ ). These data indicate that $\mathrm{dCA} 3$ may specifically drive context-induced reinstatement via inputs to LS.

\section{Chemogenetic Inhibition of Ventral Hippocampal Inputs to LS does not Block Reinstatement Behavior}

Our data revealed that B-M microinjections in LS attenuated both context- and cue-induced reinstatement of cocaine 


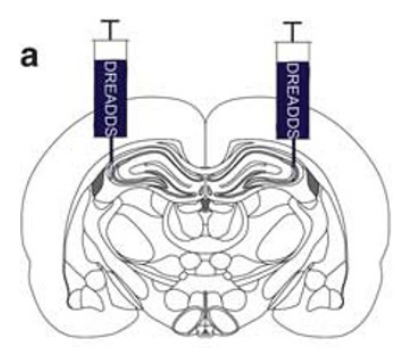

b
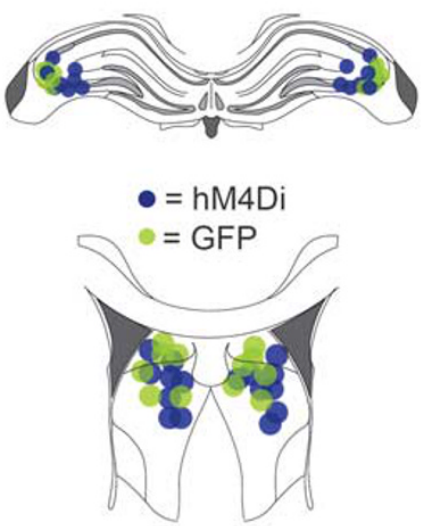

C

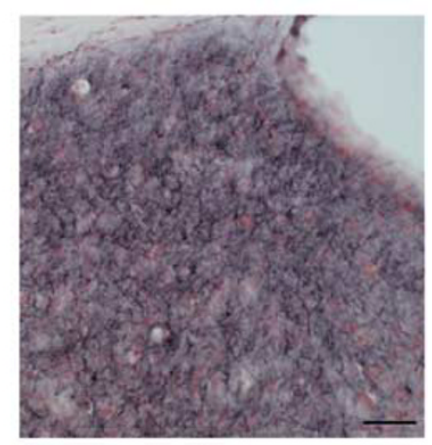

d
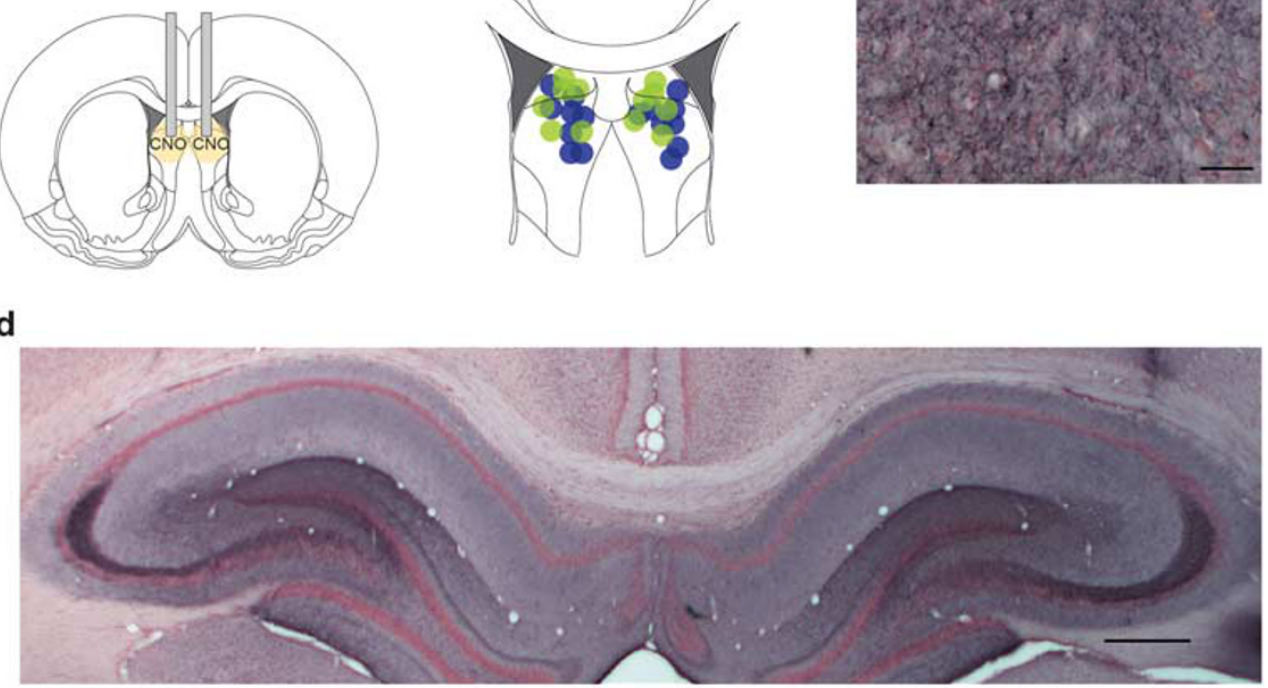

e

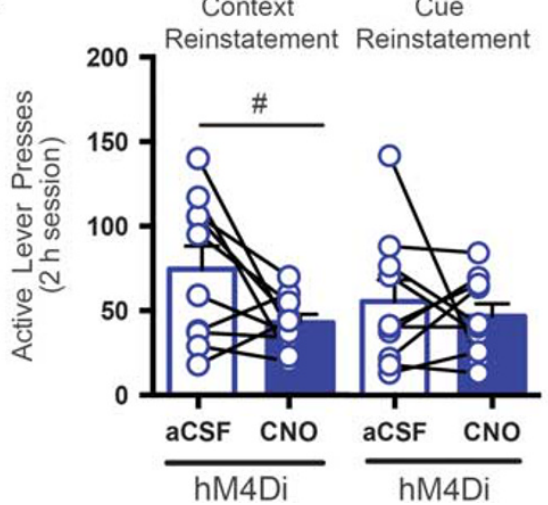

f

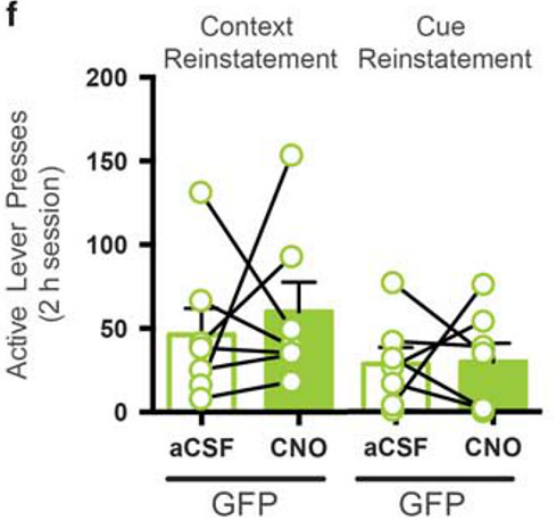

Figure 4 Dorsal hippocampus inputs to lateral septum (LS) drive context- but not cue-induced reinstatement. (a) Illustration of procedure for DREADD hM4Di viral injections into dorsal hippocampus and CNO locally infused onto hM4Di-expressing dorsal hippocampal terminals in LS. (b) The schematic representation of dorsal hippocampus (upper panel, $2.92 \mathrm{~mm}$ posterior to bregma, Paxinos and Watson, 2007) shows the central site of injection of the DREADD virus. The schematic of LS (lower) shows bilateral microinjector sites collapsed onto one rat atlas section (0.72 mm anterior to bregma, Paxinos and Watson, 2007). Blue circles represent the locations of injections of rats that received a viral vector expressing the gene of the hM4Di DREADD receptor ('hM4Di'). Green circles represent the locations of injections of rats that received a viral vector without hM4Di receptor gene (GFP). (c) Representative photomicrograph of hM4Di-expressing dCA3 terminals in LS seen with an antibody against the HA-tag fused to the hM4Di receptor (purple/black terminals) and counterstained with neutral red. Scale bar, $100 \mu \mathrm{m}$. (d) Representative photomicrograph of bilateral DREADD injection into dCA3 of hippocampus (purple/black stain). As above, an antibody against the HA-tag fused to the hM4Di receptor stained the DREADDs and tissue was counterstained with a neutral red Nissl stain. Scale bar, 500 Hm. (e) Inhibiting hM4Di-expressing dorsal hippocampal terminals in LS with local CNO (solid blue bars) showed a strong trend to attenuate active lever responding during context-induced, but not cue-induced, reinstatement of cocaine seeking compared to the same rats that received aCSF (open blue bars) microinjections $(n=10$, effect of drug: $P=0.06)$. Circles show individual data that overlay mean \pm SEM bar graphs. ( $f$ ) There were no effects of CNO (solid green bars) vs aCSF (open green bars) microinjections on GFP rats during either reinstatement modality $(n=7, P>0.05$ ). Circles show individual data that overlay mean \pm SEM bar graphs.

seeking, but CNO microinjections onto hM4Di-expressing $\mathrm{dCA} 3$ terminals in LS only attenuated context-induced reinstatement. These data imply functional specificity of inputs to LS. Therefore, we next examined whether other afferents to LS that may be involved in cue-induced reinstatement behavior. Basolateral amygdala (BLA) seemed possible because of its involvement in conditioned cue associations (Maren and Fanselow, 1996; Meil and See, 1997; Stefanik and Kalivas, 2013), despite it being a sparse projection to LS (Risold and Swanson, 1997). However, 
BLA did not show enhanced Fos activity in its inputs to LS during cue-induced or context-induced reinstatement (Supplementary Figure S4; $F_{2,26}=7.3, P=0.5$ ).
We then hypothesized that ventral hippocampus inputs to LS may be involved because ventral hippocampus has a dense projection to LS (Risold and Swanson, 1997), and
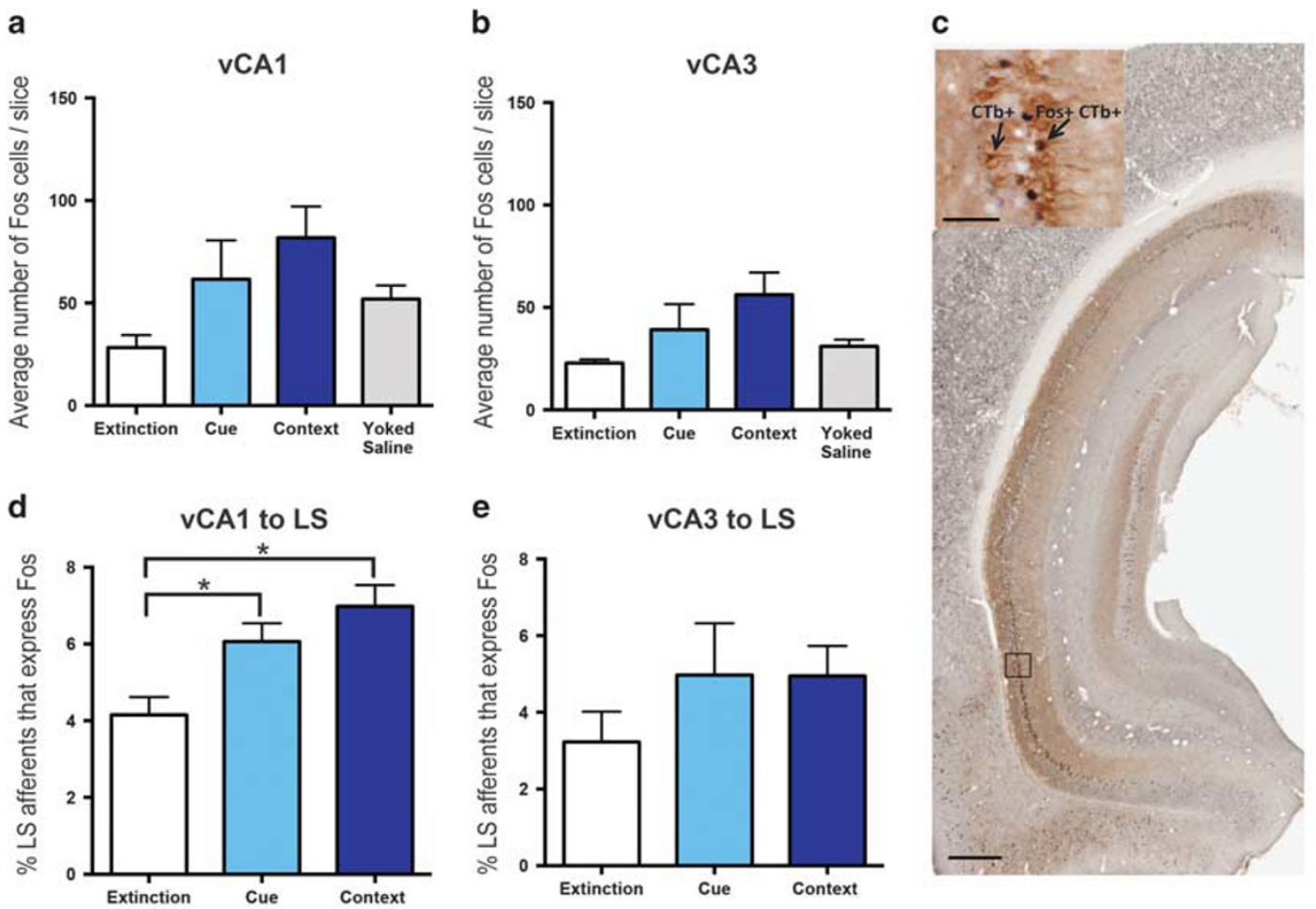

f

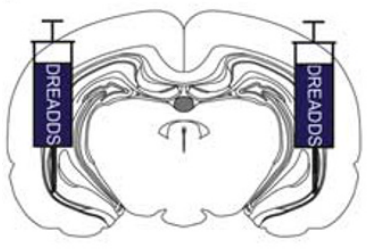

g

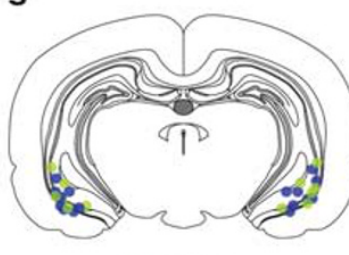

$=h M 4 D i$

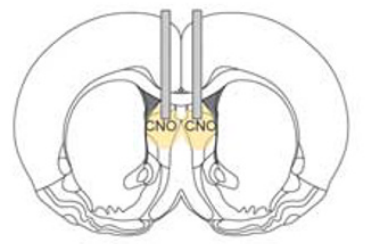

i

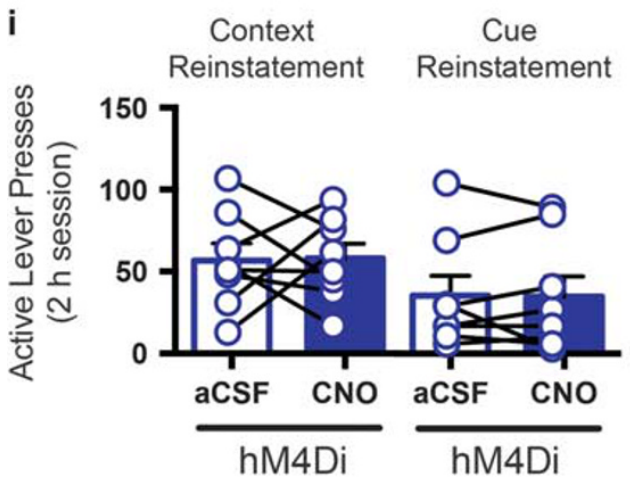

h

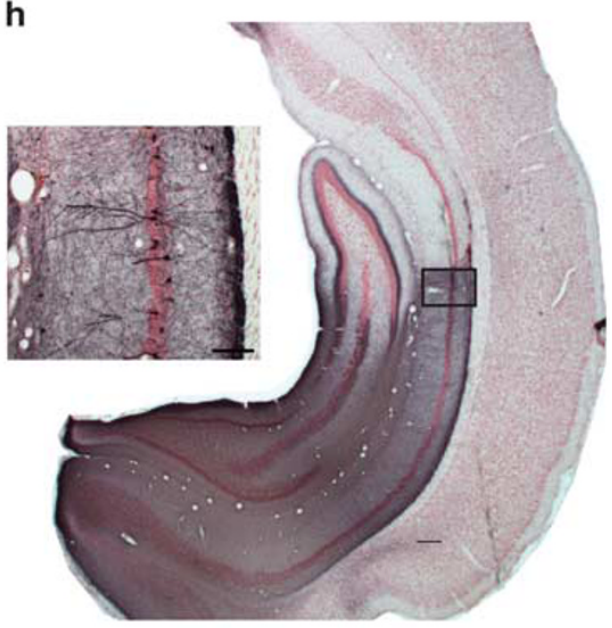

j

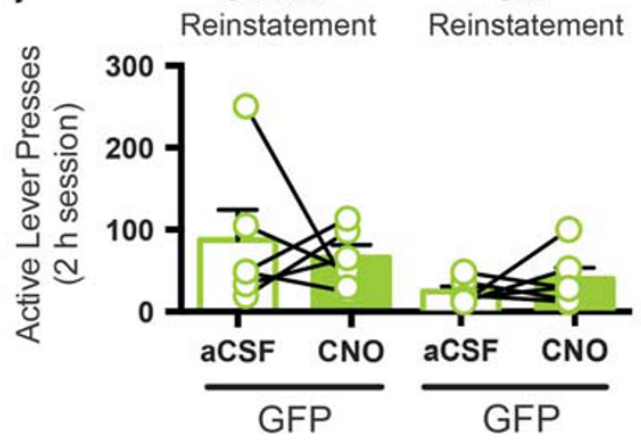


inhibition of ventral hippocampus blocks cue-induced reinstatement of cocaine seeking (Rogers and See, 2007). We assessed Fos activity in ventral CA1 and CA3 regions of the hippocampus during context- and cue-induced reinstatement, and found elevated Fos in both areas during both reinstatement modalities relative to extinction (Figure $5 \mathrm{a}$ and $\mathrm{b}$; one-way ANOVA, vCA1: $\mathrm{F}_{3,20}=2.4, P=0.097$; vCA3: $\left.F_{3,20}=1.5, P=0.11\right)$. Using the same brains injected with $\mathrm{CTb}$ in LS as above, we examined Fos activity during reinstatement of cocaine seeking in ventral CA1 and CA3 hippocampal neurons that project to LS. We found that ventral hippocampus neurons retrogradely labeled from LS expressed elevated Fos during both contextand cue-induced reinstatement relative to extinction (Figure $5 \mathrm{c}-\mathrm{e}$; vCA1 to LS: $\mathrm{F}_{2,26}=8.0, P=0.002$; vCA3 to LS: $\mathrm{F}_{2,26}=1.0, P=0.4$ ).

We then tested with chemogenetics whether ventral hippocampal projections to LS might contribute to cued reinstatement. We microinjected a synapsin-driven hM4Di DREADD virus ( $A A V$-hsyn-hM4Di-mcherry) into ventral hippocampus, followed later with $\mathrm{CNO}$ bilaterally onto hM4Di-expressing ventral hippocampal terminals in LS (Figure 5f-h). Microinjections of $\mathrm{CNO}$ onto hM4Diexpressing or GFP-expressing ventral hippocampal terminals in LS did not block either context-induced or cue-induced reinstatement of cocaine seeking ( $R M$ two-way ANOVA, effect of drug: Figure 5i, $\mathrm{F}_{1,14}=0.002, P=0.97$; Figure 5j, $\left.\mathrm{F}_{1,10}=0.02, P=0.90\right)$. These results indicate that contributions of the hippocampal-LS circuit to reinstatement behavior were specific to dorsal, but not ventral, hippocampus inputs to LS and involved only context-mediated relapse behavior.

\section{DISCUSSION}

This study used a novel within-subjects procedure to investigate the involvement of LS, and of hippocampal projections to LS, in reinstatement of cocaine seeking in response to a context $v s$ discrete cues previously associated with cocaine. Our data revealed that dorsal hippocampal neurons that project to LS were activated specifically during context-, but not cue-induced reinstatement. In support of these results, chemogenetic inhibition of the dorsal hippocampal-LS pathway attenuated context-, but not cueinduced reinstatement of cocaine seeking. Interestingly, we found that pharmacological inhibition of LS reduced both context- and cue-induced reinstatement of cocaine seeking. We also examined other LS afferents, and found that ventral hippocampal, but not BLA, inputs to LS were activated during both context- and cue-induced reinstatement. However, chemogenetic inhibition of the ventral hippocampal-LS circuit did not block either reinstatement modality. These results indicate a functional role of LS in multiple reinstatement modalities, and that dorsal hippocampus drives context-induced reinstatement via inputs to LS.

\section{Lateral Septum: an Important Node in Drug Abuse}

Our data support a handful of studies that implicate LS in drug addiction and relapse to several drugs of abuse including cocaine (Zahm et al, 2010), morphine (Le Merrer et al, 2007), and methamphetamine (Cornish et al, 2012). Previous findings in our laboratory demonstrated that inhibition of LS, or of LS projections to lateral hypothalamus orexin neurons, blocked preference for a cocaine-paired context (Sartor and Aston-Jones, 2012). In addition, an LSVTA circuit is Fos-activated during cue-induced reinstatement (Mahler and Aston-Jones, 2012), and disconnection of the LS-VTA pathway blocked context-induced reinstatement (Luo et al, 2011). Here, we showed for the first time that bilateral inhibition of LS blocks both context- and cueinduced reinstatement of cocaine seeking, indicating that LS is an important node in stimulus-induced relapse behavior.

Interestingly, although LS had a causal role in both context- and cue-induced reinstatement, cue-induced

Figure $5 \mathrm{CNO}$ activation of hM4Di receptors in terminals of ventral hippocampal inputs to LS does not block reinstatement. (a) The average number of Fos+ cells per brain slice in vCAI showed a trend for more Fos + cells during cue-induced (light blue bars; $n=6$ ) and context-induced (dark blue bars; $n=8$ ) reinstatement relative to extinction (white bars; $n=5$ ) or yoked saline groups (gray bars; $n=5$; one-way ANOVA, $P=0.097$ ). (b) The CA3 region of ventral hippocampus (VCA3) did not show significant differences between groups in the number of Fos + cells $(P>0.05)$. (c) Representative photomicrograph of coronal section through ventral hippocampus showing retrograde labeling after CTb injection into ipsilateral LS. Medial is to the right, dorsal is up. The black square represents the area of the magnified region of the inset. Scale bar, $500 \mu \mathrm{m}$. Inset shows magnified photomicrograph of neurons with or without Fos in VCAI labeled by retrograde tracer from LS (CTb+; brown cytoplasmic stain), Fos+ (black nuclear stain), and CTb+ neurons co-labeled with Fos (Fos+CTb+, combined brown cytoplasmic stain with black nuclear stain). Scale bar, $50 \mu \mathrm{m}$. (d) A larger percentage of ipsilateral vCA I neurons retrogradely labeled from LS expressed significant Fos during context-induced $(n=10$, dark blue bars) and cue-induced reinstatement $(n=10$, light blue bars) compared to extinction ( $n=9$, white bars) $(P=0.002)$. (e) There were no significant differences across groups in the percentages of ipsilateral vCA3 neurons retrogradely labeled from LS that expressed Fos $(P>0.05)$. SEM indicated by error bars. (f) Schematic representation of experimental design. DREADD hM4Di virus was injected bilaterally into ventral hippocampus and CNO was microinfused onto hM4Di-expressing ventral hippocampal terminals in LS. (g) The section of ventral hippocampus shows the central site of injection of the DREADD and control viruses (upper panel, $2.92 \mathrm{~mm}$ posterior to bregma). The magnified section of LS shows bilateral microinjector sites collapsed onto one rat atlas section (lower panel, frontal; $0.72 \mathrm{~mm}$ anterior to bregma, Paxinos and Watson, 2007). Blue circles represent injection sites of rats that received a vector expressing the hM4Di DREADD receptor gene (hM4Di). Green circles represent the injection sites of rats that received the same vector but contained GFP instead of the hM4Di receptor gene. (h) Representative photomicrograph of DREADD injection into ventral hippocampus as seen by a DsRed antibody against the mcherry-tag fused to the hM4Di DREADD receptor (purple/black regions) and counterstained with neutral red. Black square represents the zoomed area seen in the inset. Scale bar, I 000 um. Inset shows cell body and axonal labeling of ventral hippocampal neurons expressing the hM4Di receptor. Inset scale bar, I $00 \mu \mathrm{m}$. Whole images adjusted for brightness. (i) Microinjection of CNO among hM4Di-expressing ventral hippocampal terminals in $L S(n=8$, solid blue bars) did not affect active lever responding during context-induced or cue-induced reinstatement of cocaine seeking compared to the same rats that received aCSF microinjections (open blue bars, $P>0.05$; two-way RM ANOVA). Individual data overlay mean \pm SEM bar graphs. (j) There were also no effects of CNO (solid green bars) vs aCSF (open green bars) microinjections on rats without the DREADD receptor (GFP controls) during context-induced or cue-induced reinstatement of cocaine seeking $(n=6 ; P>0.05)$. Circles show individual data that overlay mean \pm SEM bar graphs. 
reinstatement did not induce Fos in LS. The reason for this is unclear. One possibility is that although cue-induced reinstatement requires activity in LS, the increased activation during this behavior may not be sufficient to produce Fos within LS neurons. This may indicate a permissive role for LS in cued reinstatement, where the behavior requires ongoing LS activity rather than acutely increased activation that would elicit Fos. Additional work is needed to test this and other possible reasons for this result.

Nonetheless, our Fos data support several previous findings indicating that returning to a drug-associated context enhances Fos expression in dorsal hippocampal and LS neurons (Brown et al, 1992; Neisewander et al, 2000; Trouche et al, 2016), but with a few exceptions (Kufahl et al, 2009; Neisewander et al, 2000). Differences in Fos expression in LS and hippocampus from other studies may be attributed to our unique behavioral procedure, the time at which Fos was collected in the session, extinction $v s$ abstinence training, and/or methods of Fos quantification.

The amount of Fos in LS during context-induced reinstatement did not significantly differ from that during extinction, although there was a trend especially in rostral LS (Figure 2d). This may indicate that the context during extinction remains able to activate LS neurons to a degree, ie, context information is not fully extinguished. The finding that Fos amounts were significantly higher in caudal LS in context reinstatement animals compared to yoked saline animals, with a strong trend for this also in rostral LS, is consistent with this possibility.

\section{Distinctions Between Dorsal and Ventral Hippocampus Inputs to LS}

Our data also support studies that indicate that dorsal and ventral hippocampus are anatomically and functionally distinct brain structures (Fanselow and Dong, 2010; Moser and Moser, 1998; Swanson and Cowan, 1977). For example, lesions of dorsal, but not ventral, hippocampus block spatial learning in maze tasks (Moser et al, 1995; Pothuizen et al, 2004). In addition, dorsal hippocampus lesions attenuate freezing behavior in a contextual, but not tone fearconditioning procedure (Kim and Fanselow, 1992), whereas inhibition or lesions of ventral hippocampus block freezing responses to tones and contexts associated with fear (Hunsaker and Kesner, 2008; Maren and Holt, 2004). Reinstatement behavior reveals similar functional dissociations between dorsal and ventral hippocampus: inhibition of dorsal hippocampus attenuates context-induced, but not cueinduced reinstatement of cocaine seeking (Fuchs et al, 2005), whereas inhibition of ventral hippocampus attenuates context- or cue-induced reinstatement of cocaine-, heroin-, or alcohol-seeking (Rogers and See, 2007; Lasseter et al, 2010; Bossert and Stern, 2014; Bossert et al, 2016; Marchant et al, 2016). At the circuit level, we found that chemogenetic inhibition of dorsal hippocampal inputs to LS showed a strong trend to attenuate context-, but not cue-induced reinstatement, whereas inhibition of the ventral hippocampal-LS pathway did not block either reinstatement modality. Dorsal and ventral hippocampal neurons, and their projections to LS, also differed in the extent of Fos expressed during reinstatement behaviors. Our data confirm previous findings for dissociations between the functions of dorsal and ventral hippocampus, and extend those results to indicate a role for dorsal hippocampal inputs to LS in context reinstatement.

It is notable that although inputs to LS from vCA1 expressed Fos during both context- and cue-induced reinstatement relative to extinguished cocaine seeking, inhibition of the ventral hippocampus to LS pathway did not reduce reinstatement behavior. This may indicate that, although expression of the hM4Di receptor in vCA1 was extensive as seen with immunohistochemical staining, it did not inhibit enough of the projection to LS to significantly interfere with this reinstatement behavior. It is also possible that Fos induction in this pathway does not reveal a causal role for vCA1-LS projections in reinstatement behavior. Finally, the type of virus used for the DREADD experiments may also underlie the lack of a causal role in the ventral hippocampus to LS circuit during reinstatement. Although lentivirus and AAV vectors both were used to chemogenetically inhibit the dorsal hippocampus to LS pathway, a majority of rats received the lentivirus. In contrast, only AAV was used to examine the ventral hippocampus to LS pathway. Both viruses used a synapsin promoter, but a difference in their replication, distribution, or gene expression may have contributed to the different results found for dorsal vs ventral CA1 to LS manipulations. Although the vHPC-LS circuit does not appear to have a causal role in reinstatement, ventral hippocampus projections to other targets have been found to play a causal role in reinstatement behavior (Bossert and Stern, 2014; Bossert et al, 2016; Marchant et al, 2016).

Finally, our findings may indicate that inputs from other areas may integrate in LS to drive reinstatement behavior. These may include inputs from canonical addiction-related regions such as $\mathrm{MPFC}$ or VTA (Sheehan et al, 2004), which are important for cue-induced reinstatement (Di Ciano and Everitt, 2004; McLaughlin and See, 2003). To our knowledge, these experiments are the first to functionally identify brain regions that drive drug relapse via inputs to LS. Future studies are needed to identify inputs to LS that drive cueinduced reinstatement.

In conclusion, we developed a within-subjects method to assess context- $v s$ cue-induced reinstatement, useful to characterize circuits involved in triggers for specific aspects of stimulus-induced drug relapse. Our studies were the first to functionally inhibit LS afferents during reinstatement behavior, and revealed that specific projections from dorsal hippocampus to LS mediate context-, but not cue-induced reinstatement of cocaine seeking. This extends previous findings that dorsal hippocampus is important for contextinduced behaviors by indicating that LS may be an important downstream target for these functions. Our finding that dorsal, but not ventral, hippocampus inputs to LS may drive context-induced reinstatement support other results indicating separate behavioral functions for dorsal $v s$ ventral hippocampus (Fanselow and Dong, 2010; Moser et al, 1995; Swanson and Cowan, 1977). Collectively, our results identified a neural circuit that provokes cocaine seeking triggered by drug-associated contexts, thus identifying a novel target for treating drug addiction. 


\section{FUNDING AND DISCLOSURE}

The authors declare no conflict of interest.

\section{ACKNOWLEDGMENTS}

We thank Caroline Pantazis for assistance with tissue analysis. Clozapine- $\mathrm{N}$-oxide was obtained from the NIH as part of the Rapid Access to Investigative Drug Program funded by the NINDS, and the NIMH Chemical Synthesis and Drug Supply Program. Supported by grants from the National Institute of Health to EMM (F31DA035561) and GAJ (R01DA006214).

\section{REFERENCES}

Adhikary S, Caprioli D, Venniro M, Kallenberger P, Shaham Y, Bossert JM (2017). Incubation of extinction responding and cue-induced reinstatement, but not context- or drug priminginduced reinstatement, after withdrawal from methamphetamine. Addiction Biol 22: 977-990.

Armbruster BN, Li X, Pausch MH, Herlitze S, Roth BL (2007). Evolving the lock to fit the key to create a family of $\mathrm{G}$ proteincoupled receptors potently activated by an inert ligand. Proc Natl Acad Sci USA 104: 5163-5168.

Brown EE, Robertson GS, Fibiger HC (1992). Evidence for conditional neuronal activation following exposure to a cocainepaired environment: role of forebrain limbic structures. J Neurosci 12: 4112-4121.

Bossert JM, Adhikary S, St Laurent R, Marchant NJ, Wang H-L, Morales $\mathrm{M}$ et al (2016). Role of projections from ventral subiculum to nucleus accumbens shell in context-induced reinstatement of heroin seeking in rats. Psychopharmacology 233: 1991-2004.

Bossert JM, Poles GC, Wihbey KA, Koya E, Shaham Y (2007). Differential effects of blockade of dopamine D1-family receptors in nucleus accumbens core or shell on reinstatement of heroin seeking induced by contextual and discrete cues. J Neurosci 27: 12655-12663.

Bossert JM, Stern AL (2014). Role of ventral subiculum in contextinduced reinstatement of heroin seeking in rats. Addict Biol 19: 338-342.

Cornish JL, Hunt GE, Robins L, McGregor IS (2012). Regional c-Fos and $\mathrm{FosB} / \Delta$ FosB expression associated with chronic methamphetamine self-administration and methamphetamine-seeking behavior in rats. Neuroscience 206: 100-114.

Crombag HS, Shaham Y (2002). Renewal of drug seeking by contextual cues after prolonged extinction in rats. Behav Neurosci 116: 169.

Di Ciano P, Everitt BJ (2004). Contribution of the ventral tegmental area to cocaine-seeking maintained by a drug-paired conditioned stimulus in rats. Eur J Neurosci 19: 1661-1667.

Fanselow MS, Dong H-W (2010). Are the dorsal and ventral hippocampus functionally distinct structures? Neuron 65: 7-19.

Fuchs RA, Evans KA, Ledford CC, Parker MP, Case JM, Mehta RH et al (2005). The role of the dorsomedial prefrontal cortex, basolateral amygdala, and dorsal hippocampus in contextual reinstatement of cocaine seeking in rats. Neuropsychopharmacology 30: 296-309.

Heath RG (1963). Electrical self-stimulation of the brain in man. Am J Psychiatry 120: 571-577.

Hunsaker MR, Kesner RP (2008). Dissociations across the dorsalventral axis of $\mathrm{CA} 3$ and $\mathrm{CA} 1$ for encoding and retrieval of contextual and auditory-cued fear. Neurobiol Learn Mem 89: 61-69.
Jarrard LE (1993). On the role of the hippocampus in learning and memory in the rat. Behav Neural Biol 60: 9-26.

Kim JJ, Fanselow MS (1992). Modality-specific retrograde amnesia of fear. Science 256: 675-677.

Kufahl PR, Zavala AR, Singh A, Thiel KJ, Dickey ED, Joyce JN et al (2009). c-Fos expression associated with reinstatement of cocaineseeking behavior by response-contingent conditioned cues. Synapse 63: 823-835.

Lasseter HC, Xie X, Ramirez DR, Fuchs RA (2010). Sub-region specific contribution of the ventral hippocampus to drug contextinduced reinstatement of cocaine-seeking behavior in rats. Neuroscience 171: 830-839.

Le Merrer J, Gavello-Baudy S, Galey D, Cazala P (2007). Morphine self-administration into the lateral septum depends on dopaminergic mechanisms: evidence from pharmacology and Fos neuroimaging. Behav Brain Res 180: 203-217.

Luo AH, Tahsili-Fahadan P, Wise RA, Lupica CR, Aston-Jones G (2011). Linking context with reward: a functional circuit from hippocampal CA3 to ventral tegmental area. Science 333: 353-357.

Mahler SV, Aston-Jones GS (2012). Fos activation of selective afferents to ventral tegmental area during cue-induced reinstatement of cocaine seeking in rats. J Neurosci 32: 13309-13326.

Mahler SV, Vazey EM, Beckley JT, Keistler CR, McGlinchey EM, Kaufling J et al (2014). Designer receptors show role for ventral pallidum input to ventral tegmental area in cocaine seeking. Nat Neurosci 17: 577-585.

Marchant NJ, Campbell EJ, Whitaker LR, Harvey BK, Kaganovsky $\mathrm{K}$, Adhikary S et al (2016). Role of ventral subiculum in contextinduced relapse to alcohol seeking after punishment-imposed abstinence. J Neurosci 36: 3281-3294.

Maren S, Fanselow MS (1996). The amygdala and fear conditioning: has the nut been cracked? Neuron 16: 237-240.

Maren S, Holt WG (2004). Hippocampus and Pavlovian fear conditioning in rats: muscimol infusions into the ventral, but not dorsal, hippocampus impair the acquisition of conditional freezing to an auditory conditional stimulus. Behav Neurosci 118: 97-110.

McGlinchey EM, James MH, Mahler SV, Pantazis C, Aston-Jones G (2016). Prelimbic to accumbens core pathway is recruited in a dopamine-dependent manner to drive cued reinstatement of cocaine seeking. J Neurosci 36: 8700-8711.

McLaughlin J, See RE (2003). Selective inactivation of the dorsomedial prefrontal cortex and the basolateral amygdala attenuates conditioned-cued reinstatement of extinguished cocaine-seeking behavior in rats. Psychopharmacology 168: 57-65.

Meil WM, See RE (1997). Lesions of the basolateral amygdala abolish the ability of drug associated cues to reinstate responding during withdrawal from self-administered cocaine. Behav Brain Res 87: 139-148.

Moser MB, Moser EI (1998). Functional differentiation in the hippocampus. Hippocampus 8: 608-619.

Moser MB, Moser EI, Forrest E, Andersen P, Morris RG (1995). Spatial learning with a minislab in the dorsal hippocampus. Proc Natl Acad Sci USA 92: 9697-9701.

Müller R, Bravo R, Burckhardt J, Curran T (1984). Induction of c-fos gene and protein by growth factors precedes activation of c-myc. Nature 312: 716-720.

Neisewander JL, Baker DA, Fuchs RA, Tran-Nguyen LT, Palmer A, Marshall JF (2000). Fos protein expression and cocaine-seeking behavior in rats after exposure to a cocaine self-administration environment. J Neurosci 20: 798-805.

Olds J, Milner P (1954). Positive reinforcement produced by electrical stimulation of septal area and other regions of rat brain. J Comput Physiol Psychol 47: 419-427.

Paxinos G, Watson C (2007). The Rat Brain in Stereotaxic Coordinates. 6th edn. Academic Press: London, UK. 
Pothuizen HHJ, Zhang W-N, Jongen-Rêlo AL, Feldon J, Yee BK (2004). Dissociation of function between the dorsal and the ventral hippocampus in spatial learning abilities of the rat: a within-subject, within-task comparison of reference and working spatial memory. Eur J Neurosci 19: 705-712.

Risold PY, Swanson LW (1997). Connections of the rat lateral septal complex. Brain Res Brain Res Rev 24: 115-195.

Rogers JL, See RE (2007). Selective inactivation of the ventral hippocampus attenuates cue-induced and cocaine-primed reinstatement of drug-seeking in rats. Neurobiol Learn Mem 87: 688-692.

Sartor GC, Aston-Jones GS (2012). A septal-hypothalamic pathway drives orexin neurons, which is necessary for conditioned cocaine preference. J Neurosci 32: 4623-4631.

Sheehan TP, Chambers RA, Russell DS (2004). Regulation of affect by the lateral septum: implications for neuropsychiatry. Brain Res Brain Res Rev 46: 71-117.

Smith RJ, See RE, Aston-Jones G (2009). Orexin/hypocretin signaling at the orexin 1 receptor regulates cue-elicited cocaine-seeking. Eur J Neurosci 30: 493-503.
Stefanik MT, Kalivas PW (2013). Optogenetic dissection of basolateral amygdala projections during cue-induced reinstatement of cocaine seeking. Front Behav Neurosci 7: 213.

Swanson LW, Cowan WM (1977). An autoradiographic study of the organization of the efferent connections of the hippocampal formation in the rat. J Comput Neurol 172: 49-84.

Trouche S, Perestenko PV, van de Ven GM, Bratley CT, McNamara CG, Campo-Urriza N et al (2016). Recoding a cocaine-place memory engram to a neutral engram in the hippocampus. Nat Neurosci 19: 564-567.

Young ST, Porrino LJ, Iadarola MJ (1991). Cocaine induces striatal c-fos-immunoreactive proteins via dopaminergic D1 receptors. Proc Natl Acad Sci USA 88: 1291-1295.

Zahm DS, Becker ML, Freiman AJ, Strauch S, DeGarmo B, Geisler S et al (2010). Fos after single and repeated self-administration of cocaine and saline in the rat: emphasis on the Basal forebrain and recalibration of expression. Neuropsychopharmacology 35: 445-463.

Supplementary Information accompanies the paper on the Neuropsychopharmacology website (http://www.nature.com/npp) 